\title{
Comparison of Human Primary with Human iPS Cell-Derived Dopaminergic Neuron Grafts in the Rat Model for Parkinson's Disease
}

\author{
Su-Ping Peng ${ }^{1,2} \cdot$ Sjef Copray $^{2}$
}

Published online: 5 October 2015

(C) The Author(s) 2015. This article is published with open access at Springerlink.com

\begin{abstract}
Neuronal degeneration within the substantia nigra and the loss of the dopaminergic nigro-striatal pathway are the major hallmarks of Parkinson's disease (PD). Grafts of foetal ventral mesencephalic (VM) dopaminergic (DA) neurons into the striatum have been shown to be able to restore striatal dopamine levels and to improve overall PD symptoms. However, human foetus-derived cell grafts are not feasible for clinical application. Autologous induced pluripotent stem cell (iPS cell)-derived DA neurons are emerging as an unprecedented alternative. In this review, we summarize and compare the efficacy of human iPS cell-derived DA neuron grafts to restore normal behaviour in a rat model for PD with that of human foetal primary DA neurons. The differences we observed in the efficacy to restore normal function between the 2 types of DA neuron grafts could be ascribed to intrinsic properties of the iPS cell-derived DA neurons that critically affected survival and proper neurite extension in the striatum after implantation.
\end{abstract}

Keywords iPS cells $\cdot$ Ventral mesencephalic dopaminergic neurons $\cdot$ Foetal tissue $\cdot$ Neurite extension and Parkinson's disease

Sjef Copray

j.c.v.m.copray@umcg.nl

1 Center for Neuroscience, Shantou University Medical College, Shantou, Guangdong Province, People's Republic of China

2 Department of Neuroscience, Medical Physiology, University Medical Center Groningen, University of Groningen, A. Deusinglaan 1,9713 AV Groningen, The Netherlands

\section{Introduction}

Parkinson's disease (PD) is one of the most prevalent neurodegenerative diseases, affecting 1 in 100 people over the age of 60 [1]. The disturbances in the initiation and fine-regulation of movement resulting in tremor, rigidity, akinesia and postural instability in PD patients are caused by the progressive loss of dopaminergic (DA) neurons in the substantia nigra (SN). The loss of DA neurons in the SN leads to a disruption of the nigro-striatal circuitry and a dopaminergic depletion of the striatum. The current standard therapy, L-DOPA administration, only temporarily restores striatal dopamine levels whereas deep brain stimulation only transiently reduces severe tremor $[2,3]$.

The search for more efficient and long-term effective treatment strategies for PD is still ongoing. The ground-breaking developments in stem cell research in the last decade have revived the interest for intracerebral cell transplantation as a therapeutical approach for PD. In this approach, replacement of the lost nigrostriatal dopaminergic innervation of the striatum by exogenous dopaminergic neurons is intended to restore basic dopamine levels within the striatum. Experiments on rodent and non-human primate models for PD in the 1970s and 1980s, had shown that embryonic DA neurons could survive and reinnervate the striatum after stereotactic injection [4, 5]; moreover, reduction in drug-induced rotation behaviour in'Parkinsonian' rats demonstrated that the grafted DA neurons indeed functionally integrated into the striatum and released dopamine [6-8]. Based on the findings in the experimental animal models, various clinical trials were started in the 1980s and 1990s with the striatal implantation of human foetal DA neurons with promising results. Patients with human foetal ventral mesencephalon (VM) grafts have been shown to recover from rigidity and tremors to various degrees, correlated to the restoration of intracerebral dopamine levels 
as detected by PET [9-11]; many of these patients experienced an overall improvement in quality of life $[9,10,12$, 13]. Though the outcome of striatal implantation of human foetal DA neurons in a large group of PD patients was very promising, reports on severe side effects, presumably due to suboptimal, poorly documented graft composition and/or adverse implant localization, led to a discontinuance of this approach. Apart from the complicated logistics to obtain multiple donor foetuses of the same developmental stage, the use of abortion-derived human foetal brain tissue to obtain a sufficient number of homogenous graftable DA neurons raised considerable ethical concern.

Several other sources for implantable human DA neurons have been explored ever since. DA neurons have been successfully differentiated in-vitro from human embryonic stem (ES) cells and human neural stem cells (NSCs). Besides the fact that both sources still caused ethical objections, the nonautologous origin of these cells, demanding lifelong immunosuppression after implantation, was considered a major obstacle. The ground-breaking detection of induced pluripotent stem cells (iPS cells) generated from easily accessible somatic cells (e.g. skin fibroblasts) $[14,15]$ has provided an unprecedented novel autologous source for human DA neuron grafts. The functionality of these in-vitro generated human DA neurons after intrastriatal implantation have been recently studied in rodent and non-human primate models for Parkinson's disease: in general, apart from the assessment of motor behaviour, parameters such as neuronal survival, the extent of neurite outgrowth, the coverage of the striatum with a fine network of dopaminergic terminals and the release of dopamine have been evaluated.

The aim of this review is to summarize the behavioural effects, the survival and neurite outgrowth of human iPS cell-derived DA neurons after their intrastriatal implantation in the Parkinson rat model and compare them with those observed for implanted human primary foetal DA neurons. We discuss possible explanations for the differences in efficacy, survival and outgrowth between the iPS cell-derived DA neuron grafts and the primary DA neuron grafts.

\section{Unilateral 6-OHDA Lesion Rat Model for Parkinson's Disease}

In order to study the feasibility and efficacy of grafted DA neurons as therapy for Parkinson's disease, a proper animal model is required. Among various animal models for PD (for review see [16, 17]), 6-OHDA-lesioned rats are the most often used PD animal model in DA neuron graft research. The toxin 6-hydroxy-dopamine (6-OHDA) specifically uses the catecholamine transport system of catecholaminergic neurons to enter the cells. It generates hydrogen peroxide and hydroxyl radicals and disturbs mitochondrial complex I, which leads to the production of superoxide free radicals and eventually to cell death. Stereotactical injection of 6-OHDA into the striatum of an adult rat, will induce retrograde degeneration of the SN DA neurons, usually within 2 to 3 weeks [18]. When the injection of 6-OHDA is directed into the nigrostriatal tract or in the SN itself, acute DA neuron death will be induced within $24 \mathrm{~h} \mathrm{[19]}$. The size of the lesion can be adjusted by varying the dosage of 6-OHDA [18]. The efficacy of the unilateral 6OHDA induced lesion and so the effect of a specific treatment in rats are validated by ipsilateral or contralateral circling motor behaviour after the administration of amphetamine or apomorphine [20]. The number of rotations per minute can be taken as a measure for the severity of unilateral DA loss in the striatum and the efficacy of compensation by DAproducing grafted DA neurons [21]. Besides drug-induced rotation, 6-OHDA unilateral lesions of the rodent mesotelencephalic dopamine pathways also lead to postural curvature, spontaneous rotation, contralateral sensory neglect and aberrant activity $[7,22]$. Various activity tests, such as the adjusting step test [23] and the cylinder test [24], have been used to study the non-rotational behavioural consequence of the 6-OHDA unilateral lesions and the effects of a specific treatment on that.

\section{Human Foetal Dopaminergic Neuronal Grafts}

Since the late 1970s, transplantation of embryonic VM tissue from rodents and primates in PD animal models has been extensively studied (for reviews see [25, 26]). From these fundamental studies, protocols for transplantation were established as paradigm for studies on human foetal tissue transplantation. It was established that only newly formed postmitotic DA neurons (E13 - E15 in rats) are suitable for grafting, since they have just reached a dopaminergic phenotype but do not yet have fully outgrown extensions, which makes it possible to isolate them without too much cellular damage [21, 27]. Extrapolating these data to human DA neuron grafts, human foetal VM tissue of a gestational age of 7 to 10 weeks was considered optimal. In almost all rodent studies, transplantation was performed right after tissue isolation and preparation, either dissociated into cell suspension or dissected as small tissue pieces. In this approach, DA neurons appeared to be still viable and survive the grafting procedure $[26,28]$.

Based on the promising data of rodent and primate DA neuron-rich VM tissue transplanted into PD models [4, 8, 21, 29-31], experimental studies with the implantation of human foetal DA neurons in PD models were started.

\section{Cellular Composition}

When isolating and dissociating the foetal human 'DA' VM region for Parkinson-related transplantation purposes, one 
should be aware of the actual cellular composition of this region. This is of considerable importance since in most PD transplantation studies foetal human VM cell suspensions have been used without any form of purification. In the human (foetal) VM region, SN DA neurons and ventral tegmentum area (VTA) DA neurons indeed make up around $70 \%$ of the neurons [32]. About $30 \%$ of the neurons are GABAergic; in addition 2-3\% of glutamatergic (Glu) neurons can be found in this region [32]. However, one should be aware that neurons account for only $5.6 \%$ of the total number of cells in the VM, which is even less than in most other brain areas, for instance the brain stem; $8 \%$ of the cells in this area are neurons [33]. Most of the cells in the VM region are nonneuronal and comprise astrocytes, microglia, endothelial cells etc.... The contamination of all these specific nonneuronal cell types in the ultimate graft will inevitably affect the survival and function of the implanted DA neurons and the reaction of the host in the environment around the graft. So, in fact, only a minority of cells in the non-purified foetal cell suspension from the human VM region, isolated for grafting in PD animal models, can be actually considered SN dopaminergic neurons. When human VM tissue grafts are collected from aborted foetuses, the cellular composition may be even more uncertain, due to the method of abortion used. In many cases, the abortion procedures led to a destruction of the foetus, which made it difficult to recognize brain tissue, let alone the very small specific VM portion. Even contaminating serotonergic (!) neurons have been demonstrated in the periphery of the grafts in the study by Stromberg in 1989 [34]: many 5-HTimmunoreactive terminals were found in the striatal neuropil of the host brain arising from the graft. Most studies do not even report or discuss the cell composition of the used human foetal DA neuron grafts.

\section{Efficacy of Intrastriatally Grafted Human Foetal DA Neurons in PD Animal Models}

\section{Behavioural Improvement and DA Neuron Survival}

In most studies on human foetal VM tissue transplantation in the unilaterally 6-OHDA lesion rat PD model (Table 1), a significant reduction in drug-induced rotation was observed either after grafting with a VM-derived cell suspension or small VM tissue pieces. In two rats, in the study by Brundin et al., rotation was completely annihilated and even contralateral rotation was induced at 12.5 weeks post grafting. Another two rats in this study reduced amphetamine-induced rotation by 69 and $92 \%$ at week 15.5 post grafting [35]. Rotation reduction appeared to be correlated with the number of surviving DA neurons: complete recovery was established by an average of 1200 DA neurons 21 weeks post grafting, while the 14 to 107 DA neurons found in some rats were unable to induce any behavioural change [35]. The behavioural improvement after human DA grafting occurred much later than what was observed with rat embryonic VM tissue grafts (3-4 weeks post grafting), indicating that human neurons required more time to mature and integrate into the striatum. Reduction in drug-induced rotation was only observed 15.5 weeks post grafting in rats receiving a human VM cell suspension from foetuses of gestational age of 9 weeks (PC 9 weeks), but not from foetuses isolated at gestational age between PC 11-19 weeks [35]. In another experiment with a similar set-up, intrastriatal grafting of human VM tissue with a gestational age of 6.5 weeks and 8 weeks resulted in a pronounced reduction in both amphetamine- and apomorphineinduced rotation, as well as in spontaneous rotation 18 weeks post grafting [37]. In these animals, 300 to 4249 (average 1626) DA neurons were found to survive in the grafted striatum. The studies by Brundin et al. indicated that in general between 1 and $10 \%$ of the grafted human foetal VM cell suspension (approximately 40,000 DA neurons) survived the implantation procedure $[35,37]$. Additional studies have shown that the survival of between 500 and 700 human foetal VM DA neurons are needed for full reversal of the amphetamine-induced rotation behaviour by 19-21 weeks post grafting [38, 44].

Transplantation of small VM tissue pieces in a premade cavity in the cortex also yielded significant DA neuron survival and led to a significant reduction of drug-induced rotation. In this approach, even human VM tissue pieces of a gestational age up to 12 weeks could actually survive transplantation and gave rise to a similar behavioural improvement at 3-5 months post grafting as the cell suspension grafts [34, 36]. The generation of human VM DA neurons takes place during post conception week 6.5 to 9 ; they start extending elaborated processes towards the striatum from week 10 on [45]. It is apparent that the DA neurons in young explants (PC 6.5-9 weeks), since they do not have extensive axonal and dendritic outgrowth, are hardly damaged during isolation and dissociation; in contrast, older foetal DA neurons (PC 1119 weeks) already have extensive axons, dendrites and connections, so most of them are severely damaged after dissociation and will not survive after implantation. When dissociation is omitted and small blocks of foetal VM tissue are used, the structure of most cells will be preserved, so that even tissues from PC 12 weeks can be used.

Full reversal of apomorphine-induced rotation was seldom reported. Yet, Stromberg et al. showed that this is possible with prolonged time, 7 months post grafting. The increase of D2 and D3 receptors in the striatum seems to be normalized at this time point [42]. It has been suggested that the function of SN also depends on dendritic DA release in the SN [46]. Interestingly, transplantation of DA neurons in the SN can give rise to a reduction of apomorphine-induced rotation [44]. However, it is still controversial whether the DA neurons grafted close to SN are able to extend through the meso- 


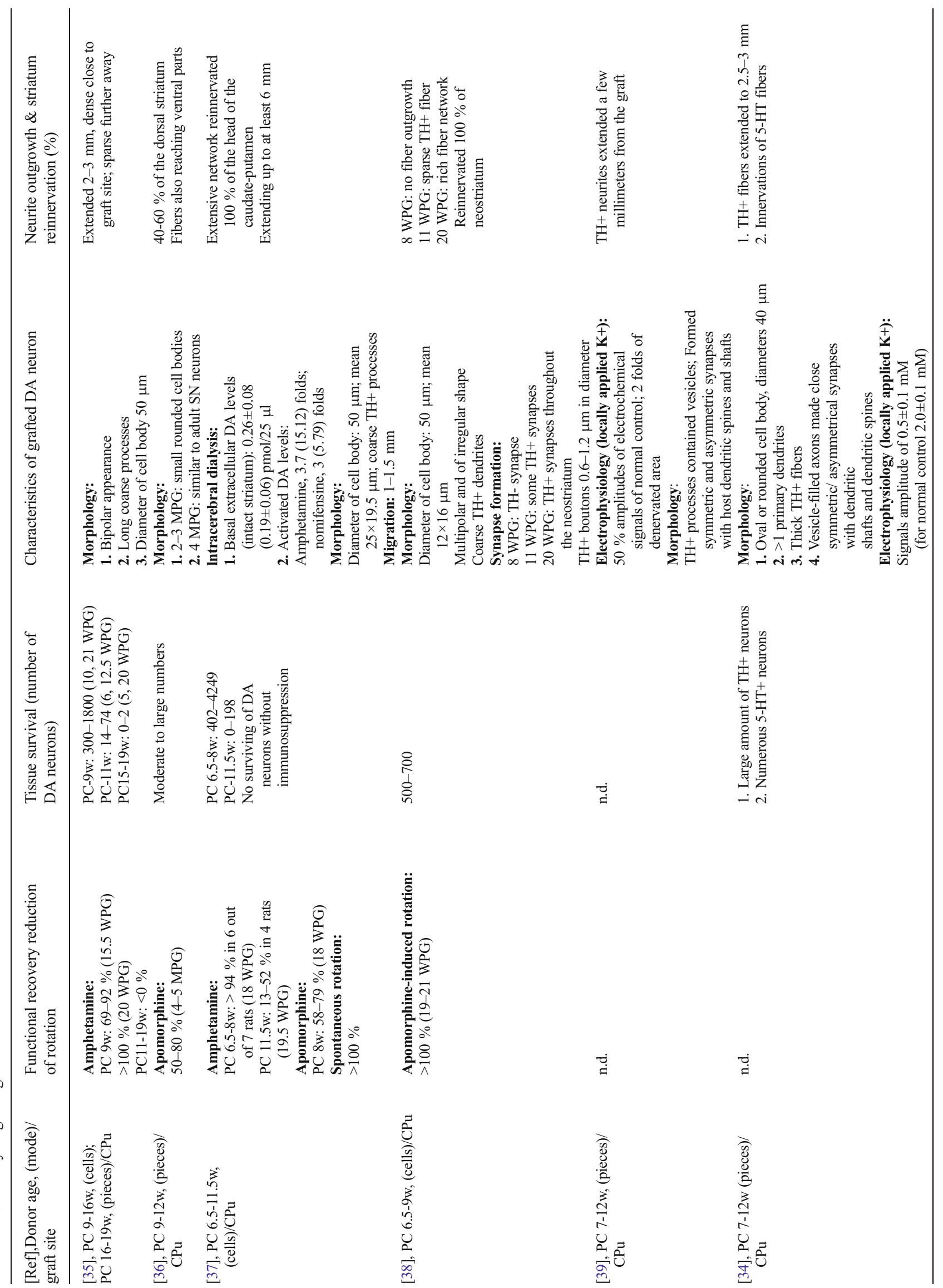




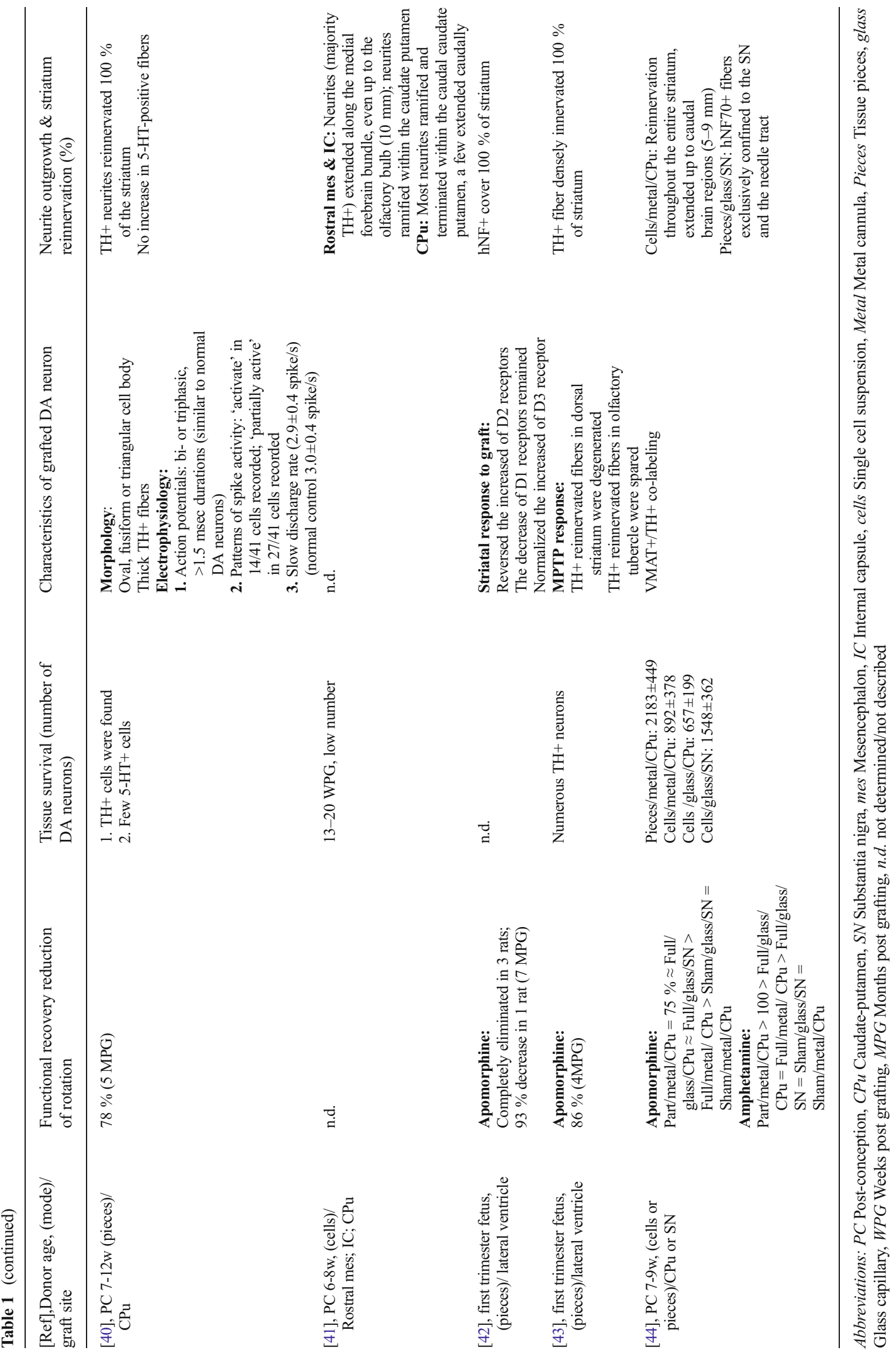


striatal pathway to reinnervate the striatum; whereas Rath et al. [44] were unable to detect such connection, both Wictorin et al. [41] and Grealish et al.[47] showed that grafts of human foetal VM of different donor ages could indeed reconstruct the meso-striatal pathway when grafted to $\mathrm{SN}$ of adult 6-OHDA lesioned rats.

\section{Characteristics of Transplanted Human Foetal DA Neurons}

It was observed that human foetal DA neurons grafted in the striatum needed a longer period to mature and integrate than those from rodents. Two to three months post grafting, the human $\mathrm{TH}+$ neurons still had an immature small rounded cell body. Up to 4 months, the DA neurons were more similar to adult SN DA neurons with $\mathrm{TH}+$ dendrites and often with fine spine-like lateral processes [36]. Two main populations of $\mathrm{TH}+$ neurons were observed: the most frequent type with small perikarya of diameter between 12 and $25 \mu \mathrm{m}$, and the rest of the population with a large perikarya diameter up to $50 \mu \mathrm{m}$ long $[37,38]$. In some cases, $\mathrm{TH}+$ perikarya were found up to $1-1.5 \mathrm{~mm}$ from the graft borders in the host striatum, indicating the ability of the grafted premature DA neuroblasts to migrate [37]. Most of the neurons were multipolar with coarse processes extending $2.5-3.0 \mathrm{~mm}$ [34] into the host striatum, and in some case, up to $6 \mathrm{~mm} \mathrm{[37]} \mathrm{or} \mathrm{even}$ 9-10 mm [41, 44]. The extent of actual reinnervation of the striatum correlated to the post grafting time. A sparse $\mathrm{TH}+$ fibre plexus was seen adjacent to the implant 11 weeks post grafting, while a rich strong $\mathrm{TH}+$ fibre network appeared to have reinnervated the entire striatum at 20 weeks (or longer) post grafting [38, 40, 42, 43].

The demonstration of reciprocal synaptic connectivity between grafted human foetal DA neurons and the host striatal interneurons confirmed the integration of the grafted human foetal DA neurons. Ultrastructural studies identified the $\mathrm{TH}+$ coarse processes as dendrites [38], providing a site for host input to the graft: graft-derived $\mathrm{TH}+$ dendrites appeared to receive non-TH labelled synaptic contacts in the host striatal neuropil. Moreover, $\mathrm{TH}+$ axons containing round or oval vesicles formed symmetric synapses, like those seen in the normal meso-striatal DA pathway, with dendritic shafts and spines and in an even higher incidence on neuronal perikarya $[34,38,39]$.

The electrophysiological characteristics of grafted human DA neurons were similar to those of DA neurons in an intact rat, which fire spontaneously in a slow firing rate $(1-10 \mathrm{~Hz})$ [48]. Some of the grafted human DA neurons showed the characteristic features of initially positively deflecting, bi- or triphasic action potentials with durations greater than $1.5 \mathrm{msec}$. The sustained activity rate of these DA neurons ranged between 0.1 and 10 spikes per second. As also found in the intact rat, some 'partially active' grafted human DA neurons exhibited action potential waveforms that were consistent with the waveforms recorded from in situ active DA neurons [40].

The functionality of the synapses formed by the grafted human DA neurons with the host striatal interneurons was validated with striatal recordings. The striatal interneurons at the site of the human foetal graft displayed slow discharge rates $(3.1 \pm 0.4 \mathrm{spikes} / \mathrm{s})$ that were almost identical to those

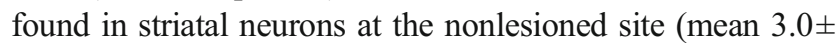
0.4 spikes/s) [40].

Intracerebral dialysis showed that the basal level of dopamine in the grafted striatum $(0.26 \pm 0.08$ pmol per $25 \mu \mathrm{l}$ of sample perfusate) of the 6-OHDA lesion rat was restored to the level observed in intact striatum $(0.19 \pm 0.06$ pmol per $25 \mu \mathrm{l}$ of sample perfusate). Grafted human DA neurons were able to respond to amphetamine stimulation with a significant increase in the DA level of the grafted striatum (3.7 times increase), although this increase was less pronounced than that observed in intact striatum (15.1 times increase) [37].

\section{Application of Human Foetal VM Tissue Transplantation in Parkinson Patients}

The promising results of intracerebral implantation of human foetal VM DA neurons in the rat model for Parkinson's disease led to open clinical trials in Parkinson patients. In these open clinical trials, many patients with human foetal VM grafts recovered from rigidity and tremors in various degrees, correlated to the restoration of the striatal dopamine level detected by PET [9-11]; the patients experienced an overall improvement in life quality $[9,10,12,13]$. Occasional post mortem studies showed the survival of DA neurons at the graft sites (between 80,000 and 135,000 TH+ neurons), and extensive reinnervation of the striatum $[49,50]$. The positive results of these initial open clinical trials sharply contrasted with the results of double-blind control NIH studies (reviewed by [51-53]): these studies failed to show any significant benefit in grafted patients up to 1 and 2 years in follow-up studies. Moreover, approximately $15 \%$ of the grafted patients in NIH study I and $56 \%$ in study II experienced severe graft-induced dyskinesias $[54,55]$. The major differences in the outcome of graft treatment between the more accurate double-blind control NIH studies and the non-standardized open trials could be ascribed to major differences in the selection of patients, in the preparation, the storage, the final composition and the size of the human foetal cell graft, the site of intrastriatal deposition and the assessment methods. Although the impure composition of the human foetal grafts did not seem to prevent significant rotation reductions in the Ungerstedt rat model for Parkinson, it may be of major relevance for clinical application. Apparently, the complex architecture, composition, size and regional differences in functionality of the human striatum represent a completely different niche than the smaller, less complicated striatum of the rat. Recently, a number of post- 
mortem brain analyses were performed on Parkinson patients that received a foetal DA graft from 3 up to 16 years ago and more of such analyses are expected in the near future. Such analyses revealed the extent of survival and the cellular composition of the graft. The first data clearly showed that the grafted dopaminergic neurons were integrated in the striatal circuitry; in addition, interestingly, some of the grafted DA neurons appeared to have developed a Lewy body pathology pointing to a prion-like transfer from surrounding cells of the responsible pathogen, most likely alpha-synuclein [56-58].

It is clear that the development of autologous induced pluripotent stem cells has now provided an unrestricted source of graftable human DA neurons that can be extensively characterized and stringently purified before actual implantation in the Parkinson patients. Clinical application of these iPS cellderived DA grafts in the near future can benefit from the ample practical experience with human foetal DA neuron intrastriatal implantations, despite their much-debated outcome. However, before clinical application, it needs to be established that DA neurons differentiated from human iPS cells show similar survival and neurite outgrowth after implantation in the PD animal models with a similar (or even a more pronounced) behavioural improvement as the primary foetal human DA neurons.

\section{Human iPS Cell-Derived Dopaminergic Neuron Grafts}

Reprogramming of human fibroblasts towards iPS cells involves a complete epigenetic resetting and a concomitant complete cellular rejuvenation. Subsequent in-vitro differentiation and maturation of human iPS cells towards a dopaminergic cell lineage will yield foetal DA neurons, with a maturational stage comparable to the human DA neurons isolated from aborted foetuses. Proper DA differentiation largely depends on the completeness of the reprogramming process and on the in-vitro protocol used for differentiation. Such a protocol should meticulously recapitulate the normal embryonic development of DA neurons, mimicking the local micro-environment. Extensive characterization and purification should lead to a much better defined DA neuron cell suspension for implantation in comparison to the human foetal primary DA cell grafts.

\section{Cellular Composition of Human iPS Cell-Derived Dopaminergic Neuronal Graft}

In order to generate proper VM DA neurons in-vitro from hiPS cells, three different differentiation strategies have been applied that have been developed for embryonic stem cells (ES Cells): the embryonic body (EB) method [59], the stromal cell co-culture method [60] and the defined-medium floor plate induced method [61] (for reviews see [62-66]). The representative procedure of each differentiation method and the expression of VM DA neuronal markers in differentiated cells are summarized in Fig. 1. Recently, several hiPS DAdifferentiation protocols have been forwarded but in general they are just modifications of the 3 mentioned strategies [67-69].

The EB-based differentiation protocol starts with the spontaneous differentiation of cultured iPS cells into EBs containing the 3 germ lineages and is followed by the selective enrichment of the neuroectoderm and the neural precursors [59]. The stromal cell co-culture method is based on the stromal cell-derived inducing activity (SDIA) that has been shown to promote neural differentiation of ESCs [70]. In both methods, neural rosette structures are formed, which are composed of neuroepithelial cells [71, 72]. The defined-medium floor plate induced method employs dual inhibition of SMAD signalling by Noggin and SB431542 to force the differentiation of human ES Cells and iPS cells into a neural cell lineage [73]. Early exposure to SHH from day 1 of differentiation directs the iPS cells to a floor plate fate [74], and in combination with the WNT signalling activator CHIR99021 (CHIR), typical VM DA neuron precursors that co-express FOXA2 and LMX1a are generated [70]. With this method, more than $70 \%$ of the cells can be committed to a floor plate cell fate $[74,75]$. The neuroepithelial cells and floor plate precursors can be induced to a VM DA neuronal fate by combination of the induction factors SHH and FGF8.

The in-vitro properties of the generated DA neurons were shown to vary between the different differentiation methods. All differentiated DA neurons were reported to be $\mathrm{TH}+$ and to co-express major VM DA neuron markers NURR1, GIRK2, PITX3 etc. [73, 75, 76]; dopamine release and slow autonomous pace-making spontaneous synaptic activity was also reported $[68,77]$. However, in contrast to the floor plate induced protocol $[78,79]$, both the embryonic body (EB) method and the stromal cell co-culture method, failed to induce FOXA2 expression during neuroepithelial celldifferentiation [47]. This later developed protocol was designed to firstly direct pluripotent cells towards floor plate cells before induction of VM DA neurons which is more similar to the in-vivo VM DA neuron development [80]. It seems the floor plate-derived DA neurons are more authentic to primary VM DA neurons [47]. Apart from more precise specification and higher efficiency, direct comparison of rosetteneuroepithelial cell-derived and floor plate cell derived DA neurons post grafting also favoured floor plate-derived DA neurons [61].

Unlike transplantation studies with human foetal VM tissue, the composition of the iPS cell-derived DA neuron grafts has been well described. By the end of in-vitro differentiation, the percentage of $\mathrm{TH}+\mathrm{DA}$ neurons derived from iPS cells varied considerably, dependent on the differentiation method 
Fig. 1 Schematic summary of the conditions for DA neuron differentiation in the representative protocols. Respectively for the EB method, the stromal cell co-culture method and the floor plate method. Based on [59] (EB), [60] (co-culture) and [61] (floor plate)
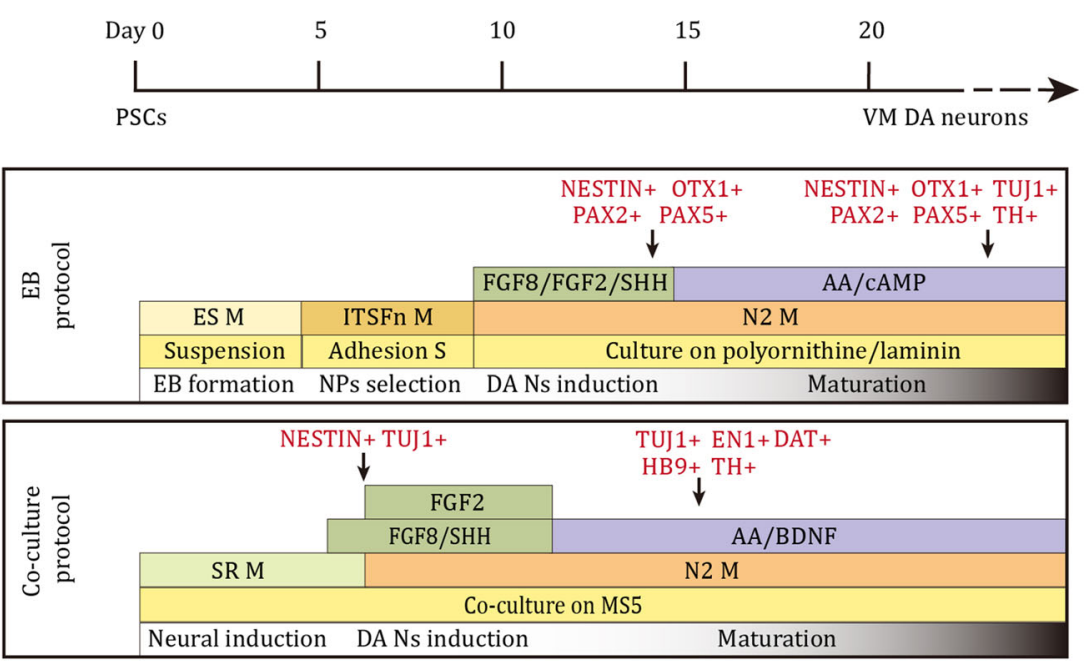

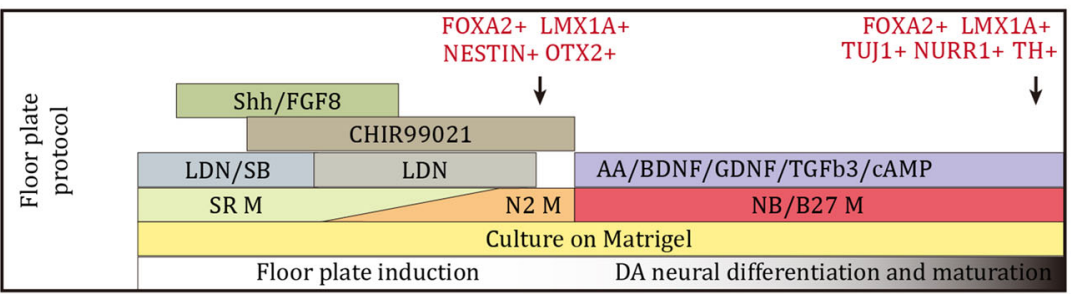

used $[61,75-77,81]$. In the study by Hargus et al., 5-10 \% of the total number of differentiated cells were neurons positive for tyrosine hydroxylase (TH): less than $1 \%$ of the $\mathrm{TH}+$ neurons co-expressed dopamine- $\beta$-hydroxylase (DBH), indicating that the vast majority of the $\mathrm{TH}+$ neurons were $\mathrm{DA}$ and not noradrenergic neurons [82]. Rhee et al. reported that 50$60 \%$ of all differentiated cells were TUJ+, of which $35-45 \%$ were $\mathrm{TH}+[76]$, whereas Kikuchi and colleagues described that, with their approach, most of the differentiated cells were TUJ+, with $85 \%$ being $\mathrm{TH}+$ [83]. Other studies reported THexpression in 18 to $54 \%$ of FOXA2+ cells after differentiation $[61,75]$. A small contamination with serotonergic, GABAergic and glutamatergic neurons and GFAP+ astrocytes were often detected $[61,76,77]$. In general, only sporadically, undifferentiated iPS cells (indicated by the expression of SSEAs, typical pluripotency cell markers) were detected after long term differentiation [77, 82] and also a few Ki67+ proliferating cells $[61,75,82]$.

\section{Efficacy of Intrastriatally Grafted Human iPS Cell-Derived DA Neurons in PD Animal Models}

\section{Behavioural Improvement and DA Neuron Survival}

The studies of human iPS cell-derived DA neuron transplantation in the rat PD model are summarized in Table 2. The reduction in rotation behaviour in the unilaterally lesioned 6OHDA rats strongly depends on the number of surviving, integrating, dopamine-producing grafted neurons. Whereas between 500 and 700 surviving foetal VM graft derived DA neurons have been shown to be sufficient to completely annihilate amphetamine-induced rotation activity, as many as 29 , 000 surviving human iPS cell-derived DA neurons appeared to be able to induce only a $50 \%$ reduction in drug-induced rotation 4 weeks post grafting; less than 1500 surviving human iPS cell-derived DA neurons resulted in not any significant change in rotation behaviour. Rhee et al. reported that around 27,000 surviving $\mathrm{TH}+$ cells were found in the 6OHDA-lesioned rats that exhibited a $47.5 \%$ reduction in rotations 8 weeks post grafting [76]. In the study by Hargus et al., the survival and integration of around 5000 human iPS cell-derived DA neurons led to a reduction in rotation of only $56 \% 16$ weeks post grafting [82]; these rats still did not show any improvement in the cylinder test and the adjustment stepping test [82]. The same study showed that rats containing only 350 surviving iPS cell-derived $\mathrm{TH}+$ cells did not show any functional improvement in apomorphine-induced rotation [82]. Similarly, the survival of around 6700 human iPS cellderived DA neurons reduced rotation behaviour to $78 \%$ 16 weeks post grafting in a study by Doi et al. [75]. Kriks et al. showed that 15,000 surviving human iPS cell-derived $\mathrm{TH}+$ DA neurons could fully compensate or even reverse amphetamine-induced rotation and improved the performance in cylinder test and stepping test 20 weeks post grafting [61]. In general, a much greater number of surviving $\mathrm{TH}+\mathrm{DA}$ neurons derived from human iPS cells is needed to give rise to significant functional improvement in comparison to human foetal DA neurons.

In most studies, between 200,000 and 400,000 human iPS cell-derived cells were stereotactically transplanted in the 


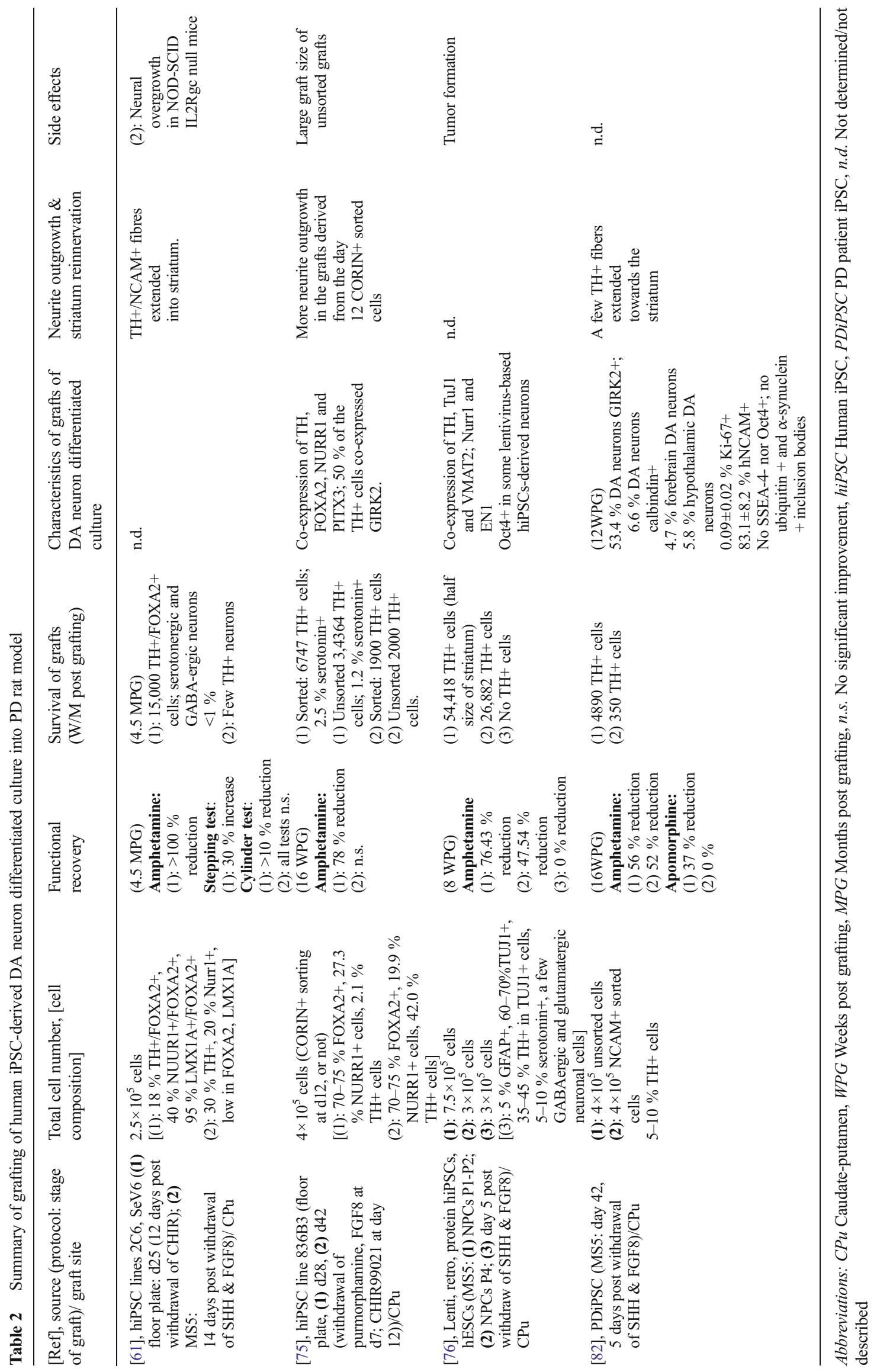


denervated striatum of the unilaterally 6-OHDA lesioned rats. Cells were transplanted mainly at two stages of differentiation. Transplantations executed with cells at the late stage of terminal differentiation resulted in a highly variable percentages of surviving DA neurons: from $0 \%$ [76], to only $1.1 \%$ [75], and 5-10\% [82]. In some studies, human iPS cell-derived cells were transplanted at an early stage of dopaminergic differentiation, containing predominantly neural precursor cells and only a very few $\mathrm{TH}+$ cells [75]. Such grafted neural precursor cells, already destined towards a VM DA neuron fate, could still proliferate before final differentiation into mature DA neuron in-situ and gave rise to a much larger (yet unpredictable) number of TH+ cells: 6700 [75], 15,000 [61] and 27,000 [76] $\mathrm{TH}+$ cells were found within grafts. The graft size in these studies was usually much bigger than that of terminal differentiation stage implantations $[75,76]$. The continuing proliferation of the neural precursor cells could result in overgrowth [76], and the early stage of differentiation could lead to the presence of undifferentiated iPS cells and so teratoma formation.

\section{Characteristics of Transplanted Human iPS Cell-Derived DA Neurons}

Analysis of the human iPS cell-derived grafts in the denervated striatum of the 6-OHDA lesion rats revealed TH+ DA neurons that were also positive for specific VM DA neuron markers, such as EN1, VMAT2, DAT [76] NURR1 [76], GIRK2, PITX3 [75, 83], and FOXA2 [61]. A detailed characterization of surviving human iPS cell-derived DA neurons showed that $53.4 \pm 6.6 \%$ of the $\mathrm{TH}+$ cells were GIRK2+ VM DA neurons, $4.7 \pm 1.0 \%$ were GABA+ forebrain DA neurons, and $5.8 \pm 1.2 \%$ were NKX2.1+ hypothalamic DA neurons [82]. However, it should be noted that in most studies the TH+ DA neurons were actually only a small portion of the surviving human iPS cell-derived cells. The majority of the iPS cellderived neurons appeared to be non-DA [76, 77, 82]; some were identified as serotonergic, GABAergic neurons [61, 76, 77]. GFAP+ astrocytes were also found within the grafts [76, 82]. Oligodendrocytes were never found, probably due to their very specific late generation during embryonic development and the consequently long specific in-vitro differentiation procedure required [76]. Ki-67+ proliferating cells could still be found in the intrastriatal graft [82]. Contamination of these cells may lead to graft overgrowth [76] or teratoma formation. When dopaminergic neural precursor cells were enriched by sorting for NCAM [69] or CORIN [75], graft overgrowth and teratoma formation were significantly reduced. No ubiquitin-positive and/or $\alpha$-synuclein-positive inclusion bodies could be detected in grafted iPS cell-derived DA and non-DA neurons generated from fibroblasts of PD patients up to 12 weeks post grafting [82]. Remarkably, exogenous pluripotent gene (OCT4, $N A N O G$ and $S O X 2$ ) expression persisted in subpopulations of
TUJ1+ neuronal cells and TH+ DA neurons derived from lentivirally reprogrammed hiPS cells even after terminal differentiation [76]. In the study described by Hargus et al. engrafted human iPS cell-derived DA neurons showed intense arborisation and branching, yet most of the DA neurons sent $\mathrm{TH}+$ fibres only towards other cells within the grafts and did not extend out to the surrounding parenchyma [82]. Kriks et al. reported that the graft core was surrounded by a halo of $\mathrm{TH}^{+}$ fibres, with some fibres occasionally extending up to $3 \mathrm{~mm}$ from the graft [61]. Non-TH+ neurites were found to project to their target areas according to their intrinsic phenotypic determination in specific and reproducible patterns [82]. In acute organotypic slices prepared from grafted rats, all transplanted neurons recorded showed spontaneous action potential currents.

\section{Human iPS Cell-Derived DA Neurons for Clinical Studies}

Based on the animal studies on cell replacement therapy for Parkinson's disease, there is no doubt that iPS cells are a prominent source for transplantable DA neurons, but the procedure to generate VM DA neurons from iPS cells in-vitro is as yet not acceptable for clinical application. A reliable quality check for human iPS cell-derived DA neurons is yet to be established. iPSC lines vary from one another both in pluripotency and differentiation efficiency [84], which may also dependent on passage number [85]. Although iPS cells resemble ESCs, a comparative study showed that some iPSC lines have a delayed formation of EBs in comparison to ESCs [85]. Different reprogramming methods may also affect the quality of iPS cell-derived DA neurons [86]. Rhee et al. found that exogenous pluripotent genes were not completely silenced at the end of the differentiation procedure. OCT4, as well as NANOG, was still detectable in subpopulations of TUJ1+ neuronal cells and TH+ DA neurons derived from lentivirally reprogrammed hiPS cells, but not in those derived from retrovirally reprogrammed hiPS cells or protein-transfer reprogrammed hiPS cells [76]. Furthermore, unlike those from protein-transfer reprogrammed hiPS cells, NP cells derived from virally-reprogrammed hiPS cells exhibited early senescence and apoptotic cell death during passaging, which was preceded by abrupt induction of $\mathrm{p} 53$ [76]. The variation in iPSC lines may affect the efficiency in both DA neuron differentiation and their survival post grafting.

General standards for human iPS cell-derived functional and authentic VM DA neurons are yet to be established. It is apparent that the much higher number of human iPS cellderived DA neurons to achieve the same degree of functional improvement as that of human foetal VM DA neurons is related to the quality of the $\mathrm{TH}+$ cells derived from human iPS cells. The (as yet not generally standardized) validation of human iPS cell-derived VM DA neurons is based on the expression of (a combination of) specific VM DA neuron 
markers, such as the co-expression of TH, LMX1A and FOXA2 [61], the co-expression of TH and GIRK2 [81], the co-expression of TH and EN1, NURR1 and PITX3, the lack of dopamine beta-hydroxylase (DBH) co-expression with $\mathrm{TH}+$ cells [82], etc. In a few cases, the release of dopamine and the electrophysiology of iPS cell-derived DA neurons were used to confirm the resemblance with primary VM DA neurons $[61,76,87]$. Contamination of other cell types within the iPS cell-derived culture is a major concern, in that respect similar to the human foetal VM cell grafts. The establishment of a VM DA neuron purification method will be a breakthrough for cell replacement therapy for PD, for it will eliminate the presence of proliferating cells and undifferentiated iPS cells and reduce the risk of graft overgrowth or tumor formation. By reducing the presence of other cell types, potential cellular interactions and unknown effects of other neuronal cell types on (rotation) behaviour will be avoided. PSANCAM, a surface marker for neural stem/precursor cells, has been used with FAC-sorting to enrich for neural precursors [88] and floor plate-specific cell surface marker CORIN has been used to enrich for hiPS cell-derived dopaminergic neuronal precursors [75]. FAC-sorting on NCAM+/CD29 ${ }^{\text {low }}$ cells was used by Sundberg et al. to enrich VM DA neurons [69]. Neither of these cell sorting methods resulted in a pure population of mature VM DA neurons. An alternative approach could be to generate reporter lines for DA neuronal differentiation and use reporter expression for purification or selection via FAC-sorting of human dopaminergic neurons by clinically acceptable gene modification methods [89]. It is important to note that FAC-sorting at the late stage of differentiation may hamper the viability of cells post grafting. The number of surviving DA neurons was reduced by more than 10 times in the study by Hargus et al. [82].

\section{Comparison of Human Foetal With Human iPS Cell-Derived Dopaminergic Neuron Grafts}

Transplantation of human foetal VM tissue in PD animal models has provided proof-of-principle for DA neuron survival, outgrowth and integration as well as functional recovery of the grafted animal. It may serve as a gold standard for evaluating the quality of DA neurons derived from hiPS cells. We summarized the performance of hiPS cell-derived DA neuron grafts and compared it with that of human foetal VM tissue grafts in the 6-OHDA lesion rat model (Table 3). The number of surviving implanted $\mathrm{TH}+$ neurons ranged from a few hundred to around 4000 per graft in rats grafted with human foetal VM tissue. About 500-700 of viable functional DA neurons appeared to be sufficient to reverse drug-induced rotation under optimal surgery conditions $[38,44]$. On the contrary, survival of $\mathrm{TH}+$ cells from iPS cell-derived dopaminergic neuron grafts ranged from a few to 29,000 . In contrast to the human foetal DA grafts, thousands of iPS cell-derived TH+ cells appeared to be needed to fully reverse drug-induced rotation $[61,75]$.

Primary DA neurons from foetal VM tissue gave rise to extensive neurite outgrowth up to $6 \mathrm{~mm}$ [37] and reinnervated the whole volume of the striatum (Fig. 2a) [38, 40]. Neurite outgrowth of iPS cell-derived DA neurons varies from case to case but, in general, it remained relatively limited [82] or extended only $2-3 \mathrm{~mm}$ into the striatum, reinnervating only around $10 \%$ of the striatum, despite the large number of surviving $\mathrm{TH}+$ neurons (Fig. 2b) $[61,75]$. It seems likely that the more limited survival and neurite outgrowth of grafted hiPS cell-derived DA neurons in comparison to the primary human foetal DA neurons, is responsible for a lower degree of recovery of the 6-OHDA lesion rats in the drug-induced rotation behaviour. In contrast to hESC-derived DA neurons [90], data about dopamine release or the electrophysiological characteristics of hiPS cell-derived DA neurons integrated in the striatum after grafting are not yet available.

\section{Conclusions}

Although the human iPS cell-derived DA neurons seem to fulfil the major criteria for functional dopamine-releasing neurons, it is clear that they were not as effective as the human primary (foetal) DA neurons in restoring drug-induced rotation behaviour in the unilaterally 6-OHDA lesion rats. A much higher number of surviving DA neurons were required to obtain the same behavioural effects of the primary foetal DA neuron grafts. The human iPS cell-derived DA neurons showed a lower survival rate after striatal implantation and their neurite outgrowth was not as extensive as that of the human primary foetal DA neurons. Apparently, the human DA neurons obtained via differentiation from iPS cells were not identical to the primary DA neurons isolated from the VM region of the aborted foetuses. Indeed, after the reprogramming-associated complete juvenation, the iPS cellderived DA neuron may also be considered foetal, but the differentiation protocol most likely did not result in the very specific population of foetal A9 DA neurons that have the specific intrinsic properties to innervate the striatum. It is likely that, after the drastic iPS cell-reprogramming and the subsequent dopaminergic differentiation, fibroblast-derived epigenetic marks were still present interfering with a proper complete reprogramming and DA differentiation. In that respect, it is of considerable interest to note that DA neurons differentiated from human ESCs (with a similar protocol used for hiPS cells) recently showed long-term survival, efficacy in restoration of motor function as well as long extensive neurite outgrowth and wide striatal innervation after implantation in the rat PD model with a potency comparable to that seen with human foetal dopamine neurons [91]. Recently, we performed 
Table 3 Comparison of major parameters of (non-purified) human foetal and human iPSC-derived dopaminergic grafts in rat PD model

\begin{tabular}{lll}
\hline & Human foetal DA graft & Human iPSC-derived DA graft \\
\hline Composition & $\begin{array}{c}\text { DA neurons, 5-HT neurons, GABAergic } \\
\text { neurons, astrocytes, microglia [32, 34] }\end{array}$ & $\begin{array}{c}\text { DA neurons, NSCs, undifferentiated iPSCs } \\
\text { serotonergic, GABAergic neurons astrocytes } \\
{[75-77,81,82]}\end{array}$ \\
$\begin{array}{ll}\text { Percentage DA neurons in original graft } \\
\text { Survival }\end{array}$ & $5.6 \%[32,33]$ & $5-85 \%[61,75-77,81,82]$ \\
Graft overgrowth & $++++1-10 \%[35,37]$ & $+++0-12 \%[75,76,82]$ \\
Migration & - & $++[76]$ \\
Neurite outgrowth & $+[37]$ & not detected \\
Synaps formation & Long extensions $[34,36,38,40,44]$ & Short extensions [61, 82] \\
Recovery (rotation reduction, other tests) & $++[34,38]$ & not detected \\
Minimal number of TH+ cells required to full & $++++[35,38,44]$ & $++[75,76]$ \\
$\quad$ reversion of rotation behaviour & $500-700[38,44]$ & $15,000[61]$ \\
Co-expression of VM DA markers in surviving & FOXA2+, LMX1a+, EN1+, NURR1+, & TH+, GIRK2+, EN1+, NURR1+, LMX1A+, \\
$\quad$ DA neurons & GIRK2+, TH+ [47, 69] & and PITX3+ [61, 75, 76] \\
Intrastriatal DA release & $++[34,37]$ & not tested \\
Suppression of striatal interneurons & $+++[40]$ & not tested \\
Characteristic DA neuron firing in-vivo & $++++[40]$ & not tested
\end{tabular}

an in-depth comparative analysis of the expression profile of pure mouse iPS cell-derived DA neurons with that of pure mouse primary DA neurons [92]. We used Ptix3-GFP mice to enable the isolation of pure iPS cell-derived DA neurons and pure primary VM DA neurons with GFP-based FACsorting. Besides comparative global gene expression mapping, we performed comprehensive DNA methylation profiling by Reduced Representation Bisulfite Sequencing (RRBS). The mouse iPS cell-derived DA neurons indeed largely appeared to adopt characteristics of their in vivo counterparts, in morphology, dopamine production, global gene expression and $\mathrm{CpG}$ island (CGI) methylation profiles, though some fibroblast genes appeared to be expressed still [92]. However, we also found deviations in CGI methylation for a subpopulation of genes which clearly effected predominately the expression of genes associated with functional annotations such as "nervous system development", "neurogenesis" and "neuron differentiation and outgrowth" [92]. It is likely that similar iPS reprogramming "artefacts" may be responsible for the limited outgrowth and survival of the human iPS cellderived DA neurons after implantation in the rat Parkinson model. Extensive comparative expression profiling combined with genome wide epigenome analysis, like we have done for the mouse, is needed to examine in more detail the differences between human primary foetal DA neurons and the human iPS cell-derived DA neurons, although proper purification of human DA neurons may still be a bottle neck for that.

In view of the considerable undeniable clinical potential of (autologous) human iPS cell-derived DA neuron grafts, fundamental and preclinical research is still progressing which will eventually lead to a first clinical trial on a small number of Parkinson patients, presumably within 2 years. Important

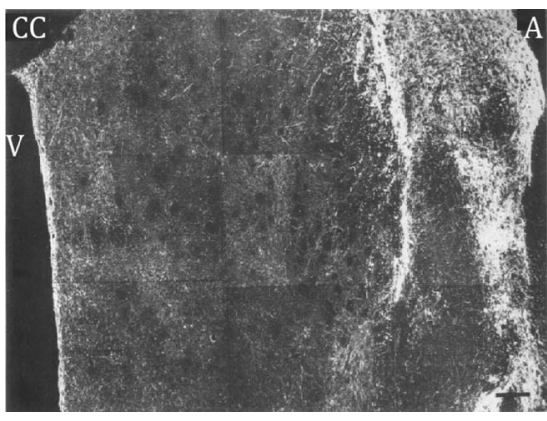

Fig. 2 Comparison of grafted human foetal VM tissue and hiPS cellderived DA neurons. a Overview of $\mathrm{TH}+$ neurites in a coronal section of the striatum 4 months after grafting human foetal VM tissue from a 10week-old foetus. The graft, filled with $\mathrm{TH}+$ cell bodies and fibres is seen at the far right, $\mathrm{TH}+$ processes radiate into host striatum and form a network that covers the whole area of striatum. b Overview of TH+ iPS

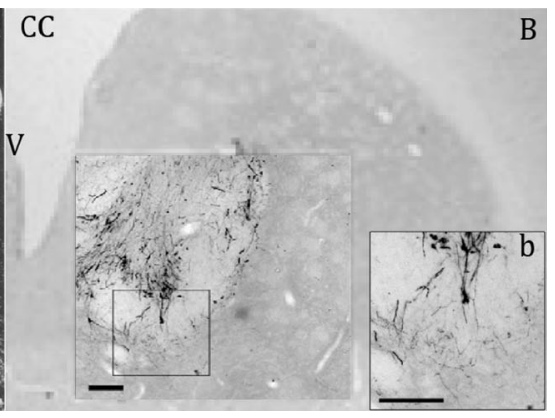

cell-derived DA neurons (unsorted) 4 months after intrastriatal transplantation. Higher magnification showing TH-positive somata and some innervation of the surrounding host striatum by graft-derived neurites $(b)$ Scale bar $=200 \mu \mathrm{m}, C C=$ corpus callosum, $V=$ ventricle. Adapted from [40, 75] 
intermediate steps towards such trial have been taken in recent studies on the transplantation of autologous iPSC-derived dopamine neurons in non-human primate model of Parkinson's disease [93, 94], showing the redundancy of the use of immunosuppressiva.

Conflict of Interest The authors declare no potential conflicts of interest.

Open Access This article is distributed under the terms of the Creative Commons Attribution 4.0 International License (http:// creativecommons.org/licenses/by/4.0/), which permits unrestricted use, distribution, and reproduction in any medium, provided you give appropriate credit to the original author(s) and the source, provide a link to the Creative Commons license, and indicate if changes were made.

\section{References}

1. de Lau, L. M., \& Breteler, M. M. (2006). Epidemiology of Parkinson's disease. Lancet Neurology, 5(6), 525-535.

2. Cotzias, G. C. (1968). L-Dopa for Parkinsonism. New England Journal of Medicine, 278(11), 630.

3. Benazzouz, A., Gross, C., Feger, J., Boraud, T., \& Bioulac, B. (1993). Reversal of rigidity and improvement in motor performance by subthalamic high-frequency stimulation in MPTP-treated monkeys. European Journal of Neuroscience, 5(4), 382-389.

4. Bjorklund, A., \& Stenevi, U. (1979). Reconstruction of the nigrostriatal dopamine pathway by intracerebral nigral transplants. Brain Research, 177(3), 555-560.

5. Bakay, R. A., Fiandaca, M. S., Barrow, D. L., Schiff, A., \& Collins, D. C. (1985). Preliminary report on the use of fetal tissue transplantation to correct MPTP-induced Parkinson-like syndrome in primates. Applied Neurophysiology, 48(1-6), 358-361.

6. Perlow, M. J., Freed, W. J., Hoffer, B. J., Seiger, A., Olson, L., \& Wyatt, R. J. (1979). Brain grafts reduce motor abnormalities produced by destruction of nigrostriatal dopamine system. Science, 204(4393), 643-647.

7. Bjorklund, A., Dunnett, S. B., Stenevi, U., Lewis, M. E., \& Iversen, S. D. (1980). Reinnervation of the denervated striatum by substantia nigra transplants: functional consequences as revealed by pharmacological and sensorimotor testing. Brain Research, 199(2), 307-333.

8. Redmond, D. E., Sladek, J. R., Jr., Roth, R. H., Collier, T. J., Elsworth, J. D., Deutch, A. Y., et al. (1986). Fetal neuronal grafts in monkeys given methylphenyltetrahydropyridine. Lancet, 1(8490), 1125-1127.

9. Lindvall, O., Brundin, P., Widner, H., Rehncrona, S., Gustavii, B., Frackowiak, R., et al. (1990). Grafts of fetal dopamine neurons survive and improve motor function in Parkinson's disease. Science, 247(4942), 574-577.

10. Freed, C. R., Breeze, R. E., Rosenberg, N. L., Schneck, S. A., Kriek, E., Qi, J. X., et al. (1992). Survival of implanted fetal dopamine cells and neurologic improvement 12 to 46 months after transplantation for Parkinson's disease. New England Journal of Medicine, 327(22), 1549-1555.

11. Lindvall, O., Sawle, G., Widner, H., Rothwell, J. C., Bjorklund, A., Brooks, D., et al. (1994). Evidence for long-term survival and function of dopaminergic grafts in progressive Parkinson's disease. Annals of Neurology, 35(2), 172-180.

12. Henderson, B. T., Clough, C. G., Hughes, R. C., Hitchcock, E. R., \& Kenny, B. G. (1991). Implantation of human fetal ventral mesencephalon to the right caudate nucleus in advanced Parkinson's disease. Archives of Neurology, 48(8), 822-827.

13. Spencer, D. D., Robbins, R. J., Naftolin, F., Marek, K. L., Vollmer, T., Leranth, C., et al. (1992). Unilateral transplantation of human fetal mesencephalic tissue into the caudate nucleus of patients with Parkinson's disease. New England Journal of Medicine, 327(22), 1541-1548.

14. Takahashi, K., \& Yamanaka, S. (2006). Induction of pluripotent stem cells from mouse embryonic and adult fibroblast cultures by defined factors. Cell, 126(4), 663-676.

15. Takahashi, K., Tanabe, K., Ohnuki, M., Narita, M., Ichisaka, T., Tomoda, K., et al. (2007). Induction of pluripotent stem cells from adult human fibroblasts by defined factors. Cell, 131(5), 861-872.

16. Betarbet, R., Sherer, T. B., \& Greenamyre, J. T. (2002). Animal models of Parkinson's disease. Bioessays, 24(4), 308-318.

17. Jackson-Lewis, V., Blesa, J., \& Przedborski, S. (2012). Animal models of Parkinson's disease. Parkinsonism \& Related Disorders, 18(Supplement 1), S183-S185.

18. Przedborski, S., Levivier, M., Jiang, H., Ferreira, M., JacksonLewis, V., Donaldson, D., et al. (1995). Dose-dependent lesions of the dopaminergic nigrostriatal pathway induced by intrastriatal injection of 6-hydroxydopamine. Neuroscience, 67(3), 631-647.

19. Faull, R. L., \& Laverty, R. (1969). Changes in dopamine levels in the corpus striatum following lesions in the substantia nigra. Experimental Neurology, 23(3), 332-340.

20. Ungerstedt, U. (1968). 6-Hydroxy-dopamine induced degeneration of central monoamine neurons. European Journal of Pharmacology, 5(1), 107-110.

21. Bjorklund, A., Schmidt, R. H., \& Stenevi, U. (1980). Functional reinnervation of the neostriatum in the adult rat by use of intraparenchymal grafting of dissociated cell suspensions from the substantia nigra. Cell and Tissue Research, 212(1), 39-45.

22. Dunnett, S. B., Bjorklund, A., Stenevi, U., \& Iversen, S. D. (1981). Grafts of embryonic substantia nigra reinnervating the ventrolateral striatum ameliorate sensorimotor impairments and akinesia in rats with 6-OHDA lesions of the nigrostriatal pathway. Brain Research, 229(1), 209-217.

23. Yang, D., Zhang, Z. J., Oldenburg, M., Ayala, M., \& Zhang, S. C. (2008). Human embryonic stem cell-derived dopaminergic neurons reverse functional deficit in parkinsonian rats. Stem Cells, 26(1), 55-63.

24. Kim, J. H., Auerbach, J. M., Rodriguez-Gomez, J. A., Velasco, I., Gavin, D., Lumelsky, N., et al. (2002). Dopamine neurons derived from embryonic stem cells function in an animal model of Parkinson's disease. Nature, 418(6893), 50-56.

25. Brundin, P., Strecker, R. E., Lindvall, O., Isacson, O., Nilsson, O. G., Barbin, G., et al. (1987). Intracerebral grafting of dopamine neurons. Experimental basis for clinical trials in patients with Parkinson's disease. Annals of the New York Academy of Sciences, 495, 473-496.

26. Perlow, M. J. (1987). Brain grafting as a treatment for Parkinson's disease. Neurosurgery, 20(2), 335-342.

27. Brundin, P., Isacson, O., \& Bjorklund, A. (1985). Monitoring of cell viability in suspensions of embryonic CNS tissue and its use as a criterion for intracerebral graft survival. Brain Research, 331(2), 251-259.

28. Emgard, M., Karlsson, J., Hansson, O., \& Brundin, P. (1999). Patterns of cell death and dopaminergic neuron survival in intrastriatal nigral grafts. Experimental Neurology, 160(1), 279288.

29. Dunnett, S. B., Bjorklund, A., Schmidt, R. H., Stenevi, U., \& Iversen, S. D. (1983). Intracerebral grafting of neuronal cell suspensions. V. Behavioural recovery in rats with bilateral 6-OHDA lesions following implantation of nigral cell suspensions. Acta Physiologica Scandinavica. Supplementum, 522, 39-47. 
30. Arbuthnott, G., Dunnett, S., \& MacLeod, N. (1985). Electrophysiological properties of single units in dopamine-rich mesencephalic transplants in rat brain. Neuroscience Letters, 57(2), 205-210.

31. Freund, T. F., Bolam, J. P., Bjorklund, A., Stenevi, U., Dunnett, S. B., Powell, J. F., et al. (1985). Efferent synaptic connections of grafted dopaminergic neurons reinnervating the host neostriatum: a tyrosine hydroxylase immunocytochemical study. Journal of Neuroscience, 5(3), 603-616.

32. Ungless, M. A., \& Grace, A. A. (2012). Are you or aren't you? Challenges associated with physiologically identifying dopamine neurons. Trends in Neurosciences, 35(7), 422-430.

33. Azevedo, F. A., Carvalho, L. R., Grinberg, L. T., Farfel, J. M., Ferretti, R. E., Leite, R. E., et al. (2009). Equal numbers of neuronal and nonneuronal cells make the human brain an isometrically scaled-up primate brain. Journal of Comparative Neurology, 513(5), 532-541.

34. Stromberg, I., Almqvist, P., Bygdeman, M., Finger, T. E., Gerhardt, G., Granholm, A. C., et al. (1989). Human fetal mesencephalic tissue grafted to dopamine-denervated striatum of athymic rats: light- and electron-microscopical histochemistry and in vivo chronoamperometric studies. Journal of Neuroscience, 9(2), 614 624.

35. Brundin, P., Nilsson, O. G., Strecker, R. E., Lindvall, O., Astedt, B., \& Bjorklund, A. (1986). Behavioural effects of human fetal dopamine neurons grafted in a rat model of Parkinson's disease. Experimental Brain Research, 65(1), 235-240.

36. Stromberg, I., Bygdeman, M., Goldstein, M., Seiger, A., \& Olson, L. (1986). Human fetal substantia nigra grafted to the dopaminedenervated striatum of immunosuppressed rats: evidence for functional reinnervation. Neuroscience Letters, 71(3), 271-276.

37. Brundin, P., Strecker, R. E., Widner, H., Clarke, D. J., Nilsson, O. G., Astedt, B., et al. (1988). Human fetal dopamine neurons grafted in a rat model of Parkinson's disease: immunological aspects, spontaneous and drug-induced behaviour, and dopamine release. Experimental Brain Research, 70(1), 192-208.

38. Clarke, D. J., Brundin, P., Strecker, R. E., Nilsson, O. G., Björklund, A., \& Lindvall, O. (1988). Human fetal dopamine neurons grafted in a rat model of Parkinson's disease: ultrastructural evidence for synapse formation using tyrosine hydroxylase immunocytochemistry. Experimental Brain Research, 73(1), 115-126.

39. Stromberg, I., Almqvist, P., Bygdeman, M., Finger, T. E., Gerhardt, G., Granholm, A. C., et al. (1988). Intracerebral xenografts of human mesencephalic tissue into athymic rats: immunochemical and in vivo electrochemical studies. Proceedings of the National Academy of Sciences of the United States of America, 85(21), 8331-8334.

40. van Horne, C. G., Mahalik, T., Hoffer, B., Bygdeman, M., Almqvist, P., Stieg, P., et al. (1990). Behavioral and electrophysiological correlates of human mesencephalic dopaminergic xenograft function in the rat striatum. Brain Research Bulletin, 25(2), 325334.

41. Wictorin, K., Brundin, P., Sauer, H., Lindvall, O., \& Bjorklund, A. (1992). Long distance directed axonal growth from human dopaminergic mesencephalic neuroblasts implanted along the nigrostriatal pathway in 6-hydroxydopamine lesioned adult rats. Journal of Comparative Neurology, 323(4), 475-494.

42. Stromberg, I., Adams, C., Bygdeman, M., Hoffer, B., Boyson, S., \& Humpel, C. (1995). Long-term effects of human-to-rat mesencephalic xenografts on rotational behavior, striatal dopamine receptor binding, and mRNA levels. Brain Research Bulletin, 38(3), 221233.

43. Stromberg, I., Tornqvist, N., Johansson, S., Bygdeman, M., \& Almqvist, P. M. (2001). Evidence for target-specific outgrowth from subpopulations of grafted human dopamine neurons. Microscopy Research and Technique, 54(5), 287-297.
44. Rath, A., Klein, A., Papazoglou, A., Pruszak, J., Garcia, J., Krause, M., et al. (2013). Survival and functional restoration of human fetal ventral mesencephalon following transplantation in a rat model of Parkinson's disease. Cell Transplantation, 22(7), 1281-1293.

45. Freeman, T. B., Spence, M. S., Boss, B. D., Spector, D. H., Strecker, R. E., Olanow, C. W., et al. (1991). Development of dopaminergic neurons in the human substantia nigra. Experimental Neurology, 113(3), 344-353.

46. Baker, K. A., Sadi, D., Hong, M., \& Mendez, I. (2000). Simultaneous intrastriatal and intranigral dopaminergic grafts in the parkinsonian rat model: role of the intranigral graft. Journal of Comparative Neurology, 426(1), 106-116.

47. Cooper, O., Hargus, G., Deleidi, M., Blak, A., Osborn, T., Marlow, E., et al. (2010). Differentiation of human ES and Parkinson's disease iPS cells into ventral midbrain dopaminergic neurons requires a high activity form of SHH, FGF8a and specific regionalization by retinoic acid. Molecular and Cellular Neurosciences, 45(3), 258266.

48. Zhang, T. A., Placzek, A. N., \& Dani, J. A. (2010). In vitro identification and electrophysiological characterization of dopamine neurons in the ventral tegmental area. Neuropharmacology, 59(6), 431436.

49. Kordower, J. H., Rosenstein, J. M., Collier, T. J., Burke, M. A., Chen, E. Y., Li, J. M., et al. (1996). Functional fetal nigral grafts in a patient with Parkinson's disease: chemoanatomic, ultrastructural, and metabolic studies. Journal of Comparative Neurology, $370(2), 203-230$.

50. Kordower, J. H., Freeman, T. B., Snow, B. J., Vingerhoets, F. J., Mufson, E. J., Sanberg, P. R., et al. (1995). Neuropathological evidence of graft survival and striatal reinnervation after the transplantation of fetal mesencephalic tissue in a patient with Parkinson's disease. New England Journal of Medicine, 332(17), 1118-1124.

51. Redmond, D. E., Jr. (2002). Cellular replacement therapy for Parkinson's disease-where we are today? The Neuroscientist, 8(5), 457-488.

52. Lindvall, O., \& Bjorklund, A. (2004). Cell therapy in Parkinson's disease. NeuroRx, 1(4), 382-393.

53. Bjorklund, A., \& Kordower, J. H. (2013). Cell therapy for Parkinson's disease: what next? Movement Disorders, 28(1), 110 115.

54. Freed, C. R., Greene, P. E., Breeze, R. E., Tsai, W. Y., DuMouchel, W., Kao, R., et al. (2001). Transplantation of embryonic dopamine neurons for severe Parkinson's disease. New England Journal of Medicine, 344(10), 710-719.

55. Olanow, C. W., Goetz, C. G., Kordower, J. H., Stoessl, A. J., Sossi, V., Brin, M. F., et al. (2003). A double-blind controlled trial of bilateral fetal nigral transplantation in Parkinson's disease. Annals of Neurology, 54(3), 403-414.

56. Mendez, I., Sanchez-Pernaute, R., Cooper, O., Viñuela, A., Ferrari, D., Björklund, L., Dagher, A., \& Isacson, O. (2005). Cell type analysis of functional fetal dopamine cell suspension transplants in the striatum and substantia nigra of patients with Parkinson's disease. Brain, 128(Pt 7), 1498-1510.

57. Li, J. Y., Englund, E., Widner, H., Rehncrona, S., Björklund, A., Lindvall, O., \& Brundin, P. (2010). Characterization of Lewy body pathology in 12- and 16-year-old intrastriatal mesencephalic grafts surviving in a patient with Parkinson's disease. Movement Disorders, 25(8), 1091-1096.

58. Kordower, J. H., \& Brundin, P. (2009). Propagation of host disease to grafted neurons: accumulating evidence. Experimental Neurology, 220(2), 224-225.

59. Lee, S. H., Lumelsky, N., Studer, L., Auerbach, J. M., \& McKay, R. D. (2000). Efficient generation of midbrain and hindbrain neurons from mouse embryonic stem cells. Nature Biotechnology, 18(6), 675-679. 
60. Barberi, T., Klivenyi, P., Calingasan, N. Y., Lee, H., Kawamata, H., Loonam, K., et al. (2003). Neural subtype specification of fertilization and nuclear transfer embryonic stem cells and application in parkinsonian mice. Nature Biotechnology, 21(10), 1200-1207.

61. Kriks, S., Shim, J. W., Piao, J., Ganat, Y. M., Wakeman, D. R., Xie, Z., et al. (2011). Dopamine neurons derived from human ES cells efficiently engraft in animal models of Parkinson's disease. Nature, 480(7378), 547-551.

62. Kim, D. S., Kim, J. Y., Kang, M., Cho, M. S., \& Kim, D. W. (2007). Derivation of functional dopamine neurons from embryonic stem cells. Cell Transplantation, 16(2), 117-123.

63. Khanna, A., Swistowska, A. M., Rao, M. S., \& Zeng, X. (2007). Generation and transplantation of dopaminergic neurons derived from embryonic stem cells. Current Stem Cell Research \& Therapy, 2(2), 139-147.

64. Qiu, Z., Farnsworth, S. L., Mishra, A., \& Hornsby, P. J. (2013). Patient-specific induced pluripotent stem cells in neurological disease modeling: the importance of nonhuman primate models. Stem Cells Cloning, 6, 19-29.

65. Studer, L. (2012). Derivation of dopaminergic neurons from pluripotent stem cells. In B. D. Stephen \& B. Anders (Eds.), Progress in brain research (Vol. 200, pp. 243-263). Amsterdam: Elsevier.

66. Sundberg, M., \& Isacson, O. (2014). Advances in stem-cellgenerated transplantation therapy for Parkinson's disease. Expert Opinion on Biological Therapy, 14(4), 437-453.

67. Soldner, F., Hockemeyer, D., Beard, C., Gao, Q., Bell, G. W., Cook, E. G., et al. (2009). Parkinson's disease patient-derived induced pluripotent stem cells free of viral reprogramming factors. Cell, 136(5), 964-977.

68. Hartfield, E. M., Yamasaki-Mann, M., Ribeiro Fernandes, H. J., Vowles, J., James, W. S., Cowley, S. A., et al. (2014). Physiological characterisation of human iPS-derived dopaminergic neurons. PLoS One, 9(2), e87388.

69. Sundberg, M., Bogetofte, H., Lawson, T., Jansson, J., Smith, G., Astradsson, A., et al. (2013). Improved cell therapy protocols for Parkinson's disease based on differentiation efficiency and safety of hESC-, hiPSC-, and non-human primate iPSC-derived dopaminergic neurons. Stem Cells, 31(8), 1548-1562.

70. Kawasaki, H., Mizuseki, K., Nishikawa, S., Kaneko, S., Kuwana, Y., Nakanishi, S., et al. (2000). Induction of midbrain dopaminergic neurons from ES cells by stromal cell-derived inducing activity. Neuron, 28(1), 31-40.

71. Elkabetz, Y., Panagiotakos, G., Al Shamy, G., Socci, N. D., Tabar, V., \& Studer, L. (2008). Human ES cell-derived neural rosettes reveal a functionally distinct early neural stem cell stage. Genes and Development, 22(2), 152-165.

72. Zhang, S. C., Wernig, M., Duncan, I. D., Brustle, O., \& Thomson, J. A. (2001). In vitro differentiation of transplantable neural precursors from human embryonic stem cells. Nature Biotechnology, 19(12), 1129-1133.

73. Chambers, S. M., Fasano, C. A., Papapetrou, E. P., Tomishima, M., Sadelain, M., \& Studer, L. (2009). Highly efficient neural conversion of human ES and iPS cells by dual inhibition of SMAD signaling. Nature Biotechnology, 27(3), 275-280.

74. Fasano, C. A., Chambers, S. M., Lee, G., Tomishima, M. J., \& Studer, L. (2010). Efficient derivation of functional floor plate tissue from human embryonic stem cells. Cell Stem Cell, 6(4), 336347.

75. Doi, D., Samata, B., Katsukawa, M., Kikuchi, T., Morizane, A., Ono, Y., et al. (2014). Isolation of human induced pluripotent stem cell-derived dopaminergic progenitors by cell sorting for successful transplantation. Stem Cell Reports, 2(3), 337-350.

76. Rhee, Y. H., Ko, J. Y., Chang, M. Y., Yi, S. H., Kim, D., Kim, C. H., et al. (2011). Protein-based human iPS cells efficiently generate functional dopamine neurons and can treat a rat model of
Parkinson disease. Journal of Clinical Investigation, 121(6), 2326-2335.

77. Sanchez-Danes, A., Consiglio, A., Richaud, Y., Rodriguez-Piza, I., Dehay, B., Edel, M., et al. (2012). Efficient generation of A9 midbrain dopaminergic neurons by lentiviral delivery of LMX1A in human embryonic stem cells and induced pluripotent stem cells. Human Gene Therapy, 23(1), 56-69.

78. Sonntag, K. C., Pruszak, J., Yoshizaki, T., van Arensbergen, J., Sanchez-Pernaute, R., \& Isacson, O. (2007). Enhanced yield of neuroepithelial precursors and midbrain-like dopaminergic neurons from human embryonic stem cells using the bone morphogenic protein antagonist noggin. Stem Cells, 25(2), 411-418.

79. Perrier, A. L., Tabar, V., Barberi, T., Rubio, M. E., Bruses, J., Topf, N., et al. (2004). Derivation of midbrain dopamine neurons from human embryonic stem cells. Proceedings of the National Academy of Sciences of the United States of America, 101(34), 12543-12548.

80. Ono, Y., Nakatani, T., Sakamoto, Y., Mizuhara, E., Minaki, Y., Kumai, M., et al. (2007). Differences in neurogenic potential in floor plate cells along an anteroposterior location: midbrain dopaminergic neurons originate from mesencephalic floor plate cells. Development, 134(17), 3213-3225.

81. Kirkeby, A., Grealish, S., Wolf, D. A., Nelander, J., Wood, J., Lundblad, M., et al. (2012). Generation of regionally specified neural progenitors and functional neurons from human embryonic stem cells under defined conditions. Cell Reports, 1(6), 703-714.

82. Hargus, G., Cooper, O., Deleidi, M., Levy, A., Lee, K., Marlow, E., et al. (2010). Differentiated Parkinson patient-derived induced pluripotent stem cells grow in the adult rodent brain and reduce motor asymmetry in Parkinsonian rats. Proceedings of the National Academy of Sciences of the United States of America, 107(36), 15921-15926.

83. Kikuchi, T., Morizane, A., Doi, D., Onoe, H., Hayashi, T., Kawasaki, T., et al. (2011). Survival of human induced pluripotent stem cell-derived midbrain dopaminergic neurons in the brain of a primate model of Parkinson's disease. Journal of Parkinson's Disease, 1(4), 395-412.

84. Boulting, G. L., Kiskinis, E., Croft, G. F., Amoroso, M. W., Oakley, D. H., Wainger, B. J., et al. (2011). A functionally characterized test set of human induced pluripotent stem cells. Nature Biotechnology, 29(3), 279-286.

85. Koehler, K. R., Tropel, P., Theile, J. W., Kondo, T., Cummins, T. R., Viville, S., et al. (2011). Extended passaging increases the efficiency of neural differentiation from induced pluripotent stem cells. BMC Neuroscience, 12, 82 .

86. Lohle, M., Hermann, A., Glass, H., Kempe, A., Schwarz, S. C., Kim, J. B., et al. (2012). Differentiation efficiency of induced pluripotent stem cells depends on the number of reprogramming factors. Stem Cells, 30(3), 570-579.

87. Hartfield, E. M., Yamasaki-Mann, M., Ribeiro Fernandes, H. J., Vowles, J., James, W. S., Cowley, S. A., et al. (2014). Physiological characterisation of human iPS-derived dopaminergic neurons. PLoS One, 9(2), e87388.

88. Freed, W. J., Chen, J., Backman, C. M., Schwartz, C. M., Vazin, T., Cai, J., et al. (2008). Gene expression profile of neuronal progenitor cells derived from hESCs: activation of chromosome 11p15.5 and comparison to human dopaminergic neurons. PLoS One, 3(1), e1422.

89. Momcilovic, O., Liu, Q., Swistowski, A., Russo-Tait, T., Zhao, Y., Rao, M. S., et al. (2014). Genome wide profiling of dopaminergic neurons derived from human embryonic and induced pluripotent stem cells. Stem Cells and Development, 23(4), 406-420.

90. Steinbeck, J. A., Choi, S. J., Mrejeru, A., Ganat, Y., Deisseroth, K., Sulzer, D., Mosharov, E. V., \& Studer, L. (2015). Optogenetics enables functional analysis of human embryonic stem cell-derived grafts in a Parkinson's disease model. Nature Biotechnology, 33(2), 204-209. 
91. Grealish, S., Diguet, E., Kirkeby, A., Mattsson, B., Heuer, A., Bramoulle, Y., et al. (2014). Human ESC-derived dopamine neurons show similar preclinical efficacy and potency to fetal neurons when grafted in a rat model of Parkinson's disease. Cell Stem Cell, 15(5), 653-665.

92. Roessler, R., Smalwood, S. A., Veenvliet, J. S., et al. (2014). Detailed analysis of the genetic and epigenetic signatures of iPSC-derived mesodiencephalic dopaminergic neurons. Stem Cell Reports, 2(4), 520-533.
93. Hallett, P. J., Deleidi, M., Astradsson, A., Smith, G. A., Cooper, O., Osborn, T. M., et al. (2015). Successful function of autologous iPSC-derived dopamine neurons following transplantation in a non-human primate model of Parkinson's disease. Cell Stem Cell, 16(3), 269-274

94. Morizane, A., Doi, D., Kikuchi, T., Okita, K., Hotta, A., Kawasaki, T., Hayashi, T., Onoe, H., Shiina, T., Yamanaka, S., \& Takahashi, J. (2013). Direct comparison of autologous and allogeneic transplantation of iPSC-derived neural cells in the brain of a non-human primate. Stem Cell Reports, 1(4), 283-292. 